Behavioural Sciences | Marcella Hoogeboom

\section{What team communication can tell us about team effectiveness}

Meetings. Love them or hate them, they're a regular feature of working life and there are countless studies on how most of them. Few studies, however, take a detailed view of the nature of the communication, interaction and collaboration that take place within meetings, especially team meetings. The research of Marcella Hoogeboom and Celeste Wilderom of the Netherlands is thente in timely. Based on complex adaptive systems theory, they analysed how team dynamics and information sharing in meetings can be a measure of team effectiveness.

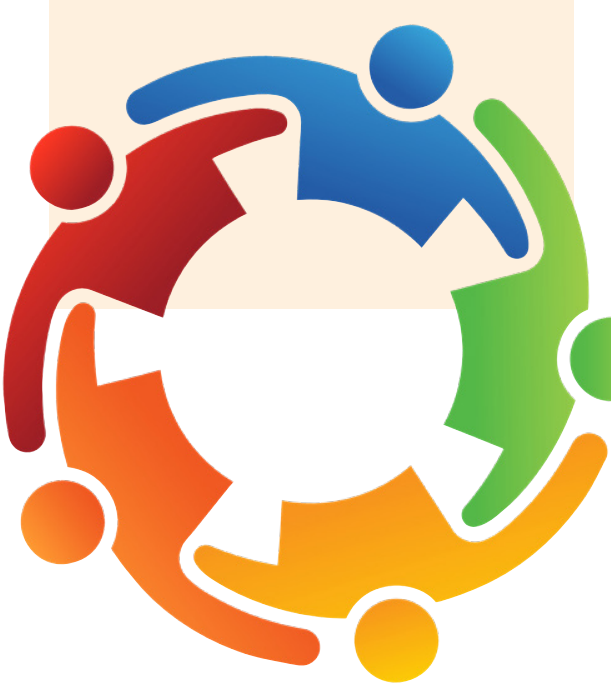

arcella Hoogeboom, assistant professor at the University of
Twente, explores how team dynamics affect team performance and that some teams show high levels of learning and are very effective, while other seemingly similar teams are less effective? Her work has been inspired by complex adaptive systems (CAS) theory which investigates how teams interact with each other in the context of vario types of tasks. It finds that the nature of team interactions changes as the types of tasks vary.

Dr Hoogebooms' research is based on the belief that the way in which team simply aggregating their pars. Teans are adaptive systems and entities that change how they operate based on the context they are operating in. Using video recordings she examines team dynamics and real-time behaviour in team meetings. The team interaction patterns, that consist of minute behaviours, observed on film, are subsequently coded effectiveness and performance.

\section{A COMPLEX ADAPTIV}

\section{SYSTEMS APPROACH}

While a substantial amount of business leadersip attribuas hr focused on believes that there is a lack of analysis into behavioural interactions of leaders defined micro-behaviours. These . boss wants it like that", and providing negative feedback, for exmple "I'm not happy with the way you did this". Other micro-behaviours included task monitoring, for example, "Are we going to meet the deadline?", and showing personal interest, for example, "You must be happy about that". Micro-behaviours also included body language, for example whether team members looked bored, nodded, or talked to others during the meeting.

Micro-behaviours were groupe into four meta-categories, or bigger conglomerates of behaviours that include similar type of spectic behaviours, based on current leadership theory litera transactional entaling communication that is focused on setting performance expectations and goals and correcting deviations when performance levels are not being met, whether it was ransformational, meaning communication which involves encouragement inspiration and motivation to innovate or create change, or an initiating structure type behaviour, meaning task-based communication, or whether it represented counterproductive behaviour.

sing theme pattern recognition software to analyse the results, team interaction patterns were identified. In otal, 110,835 behavioural events were coded, and 7,879 behavioural patter this indicates that teams tend to engage in much patterned behavio that is patterns of team behaviours th are constantly recurring while interacting with others, although they are often not aware of it. Creating more awareness of the patterns of behaviour can enhance the teams' understanding of how to become more effective.

\section{HOW DO TEAMS INTERACT?} Dr Hoogeboom set out to test six hypotheses about the way teams interact in meetings. Four hypotheses were confirmed. Results confirmed that information sharing explains the reationship between recun g pattens of team interaction and team efrectiveness.

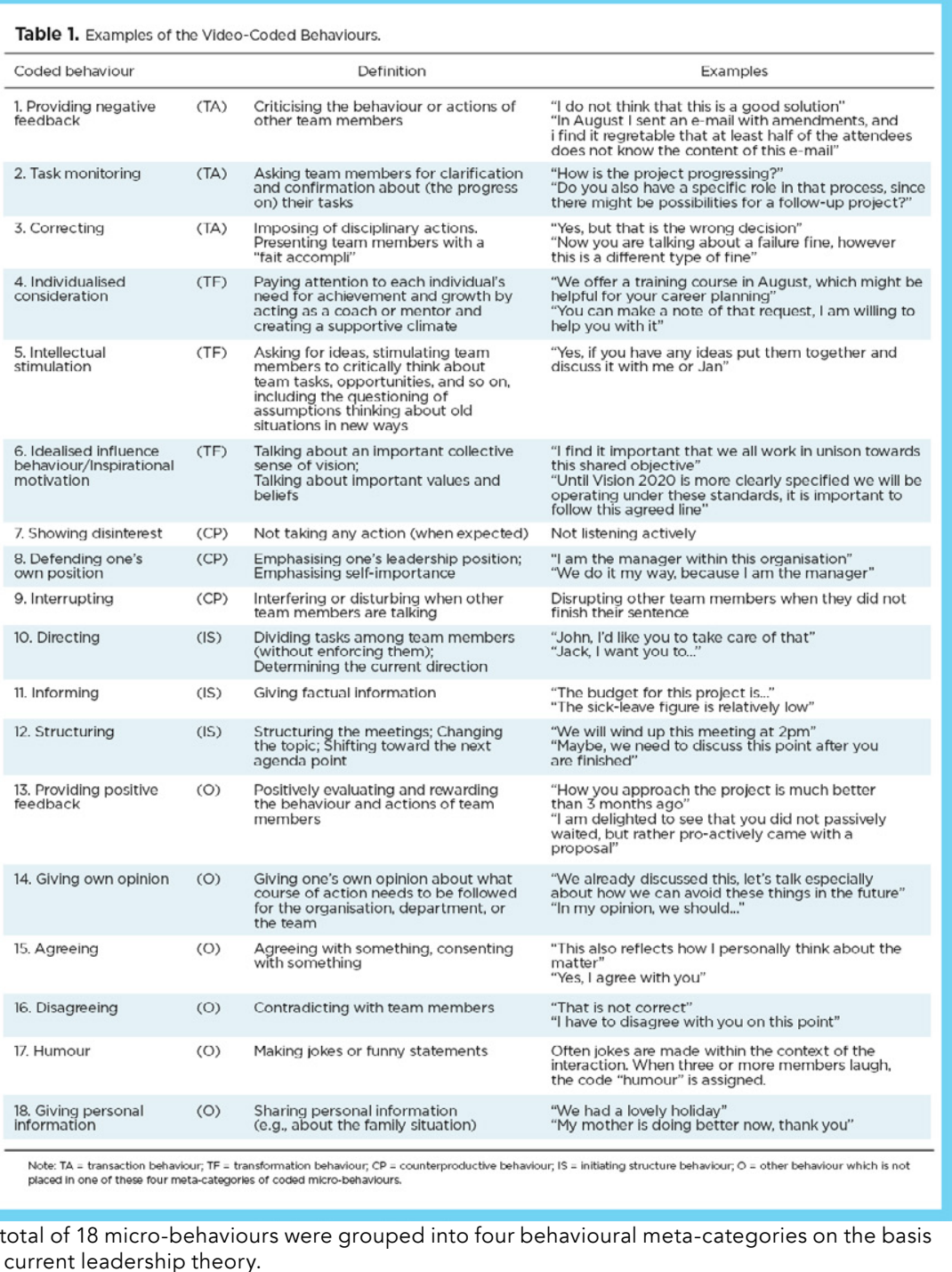

The dynamics of team interaction heavily influence the performance of a team.

participative team interaction pattern
and team effectiveness. Thus, when a team interacts in a certain way, this influences the degree of information sharing in the team, impacting their performance. Recurring patterns of team interaction were negatively related with team information sharing and performance, while engaging in participative interaction patterns was positive for higher levels of information sharing and performance. The context of the task dictated the strength of the participative team interaction patterns

Notably, the study highlights how critical it is for teams working in highly type tasks should avoid engaging in recurring patterns of behaviour; this wi sharing, and therefore performance, over time. The results showed that a high participation level from all. members when they are interacting (e.g. more frequent shifts in who is speaking) supports greater information sharing and higher performance.

The results did not confirm the hypothesis that heterogeneous team interaction patterns (i.e. interaction patterns with high levels of behavioural variation) are positively related to team effectiveness through information influences idea that task context 


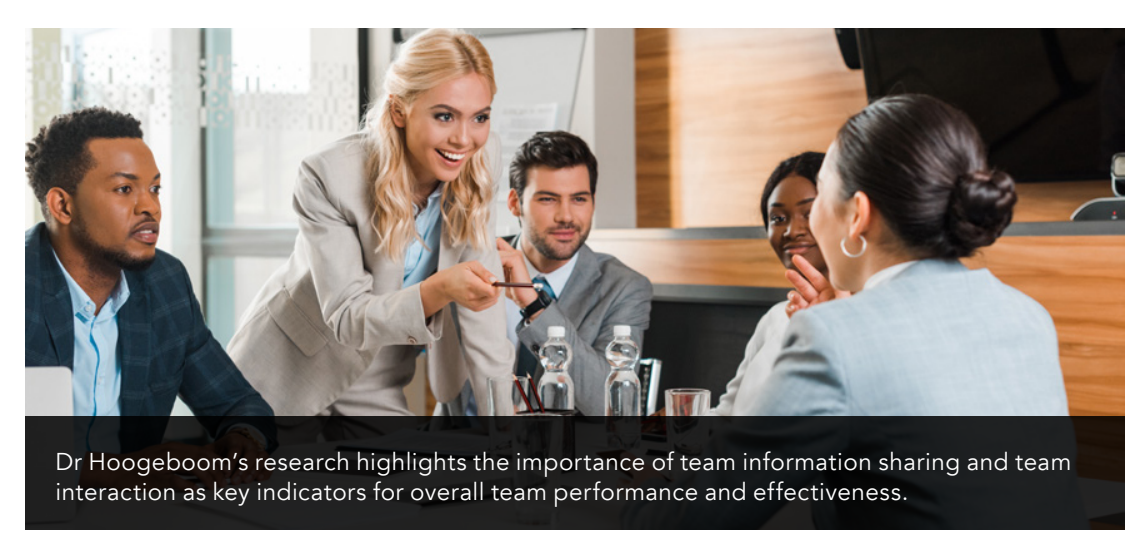

diverse team interaction patterns and team information sharing was also not confirmed.

Other findings, where the behavioural content of the team interaction patterns were examined, included and "initioting structu" "behaviou were the most dominant types of behaviour in team interaction pattens, whereas "transformational" behaviou was rarely part of the interaction patterns. Additionally, least effective teams demonstrated much more counterproductive behaviour within their interaction patterns (38\%), compared with highly effective teams $(7 \%)$. This implies that some of the patterned interactions

members tend to tailor their interactions to the nature of the work at hand. In a nonroutine or knowledge-intensive task context the effects of routinised or mor rigid and recurring forms of interaction are even more detrimental for the amount of information sharing and performance. memer switches during team meeting mentcing team task context."

This study also finds different interaction patterns in the most and least effective teams. Dr Hoogeboom asserts: "The most effective teams primarily have interaction patterns that are characterised by task-directed behaviours, such as
information sharing and monitoring."

The most effective teams primarily have interaction patterns that are characterised

by task-directed behaviours, such as

information sharing and monitoring.

are indeed functional. Using content light on which interctis shed more unctional and dysfunctional.

\section{IMPORTANCE OF TEAM} INFORMATION SHARING

Notably, this research highlights the importance of team information sharing and team interaction as key indicators for overall team performance and effectiveness, suggesting why some teams perform better than others. $\mathrm{Dr}$ Hoogeboom proposes that behavioural coding through a "meaningful taxonomy" contributes to our understanding of what interactwith one another She says: "Tom

Regarding counterproductive behaviours she writes: "Even though the most or recurring forms of team interaction when they engage in it their interactions are highly functional and they engage much less in cycles of counterproductive type interactions."

Dr Hoogeboom's video-based examination of real-time behavioura data on team interaction in the light of complex adaptive systems theory provides significant insight into what makes a team more than just a group of employees. It shows the importan of team interaction for overall team show evidence in this study that participative team interaction patterns se associated with a team's extensive team effectiveness in both routine and nonroutine task contexts."

\section{PRACTICAL APPLICATION}

OF THE FINDINGS

Dr Hoogeboom's findings provide vital

insights for enhancing team training and

development programmes; they provide a system for how to build and sustain a the specific task context. Developmental programmes can be targeted at

employees based on the roles that they perform, and what interaction patterns will best support high performance in hat environment. For example, specif draining can be offered on the task-

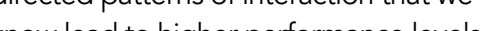

Her findings provide critical insights for the leaders of teams, who need to
understand the significance of team information sharing and their recurring patterns of interaction, if they wish to reach high performance standards.

Leaders of teams who perform nonroutine work need to be creative in keeping their information sharing mechanisms feeling fresh, new and therefore more effective. Leaders can also be coached on how best to encourage high participation levels from their team members based on the study's findings, so that no team member feels 'out of the loop'. Leadership training more agile and adaptive so that they rore agle and a interacting for their teams.

Leaders and team members as well as coaches can use Dr Hoogeboom's syste of behaviour coding to assess their individual interactions and how these are supporting or detracting from the team's performance. This is because the codebook specifically includes behaviours that can be actually observed in a workplace environment.

She concludes: "The study shows that teams who can adapt quickly and who are more llexible or open toward each member's input, especially whe working in a n's in levels of performance."

\section{Behind the Research}

\section{Dr Marcella Hoogeboom}

E: a.m.g.m.hoogeboom@utwente.nl T: $\quad$ +31 (0) 534893984 T: +31 (0) 6-200 66194

Research Objectives

Marcella Hoogeboom's main research interests include: Leader-follower dynamics; Team routine behavioural patterns and dynamics; Team learning, Facilitation of

\section{Detail}

\section{Marcella Hoogeboom}

University of Twente

Management and Social Sciences Department of Educational Sciences / Human Resource Development

$7522 \mathrm{NB}$, Ensched

Bio

Marcella Hoogeboom currently works as an Assistant Professor at the University of Twente, department Educational Science \& Technology, faculty Behavioral Management and Social Sciences. In December 2019, she obtained a Cum Laude Ph.D. degree from the University of Twente (promotor Prof Dr Wilderom), Enschede, The Netherlands.

Collaborators

Prof Dr C.P.M. Wilderom

\section{UNIVERSITY OF TWENTE.}

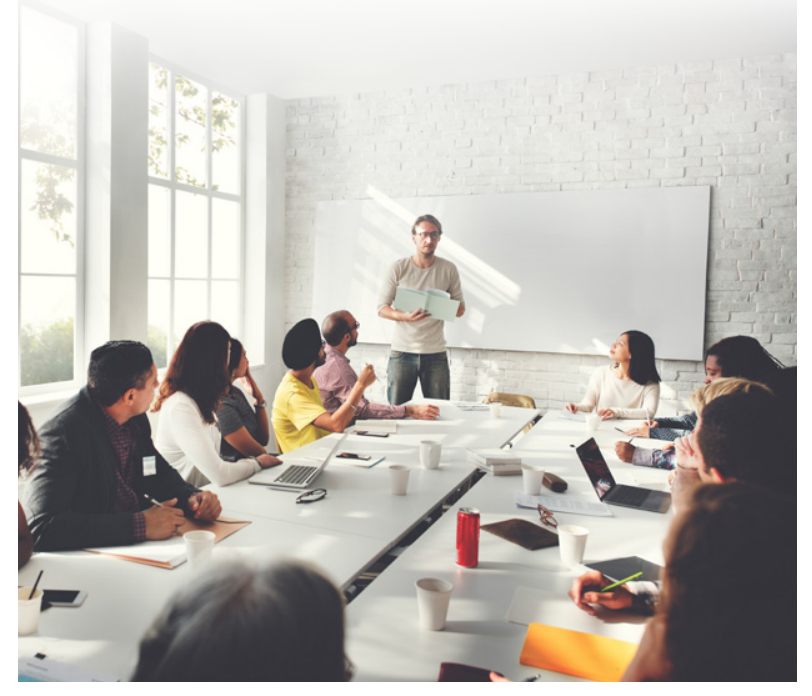

\section{References}

Gibson, C.B., Cooper, C.D., \& Conger, J.A. (2009). Do you see what we see? The complex effects of perceptual distance between leaders and teams. Journal of Applied Psychology, Vol 94, 62-76. https://doi.apa.org/ doilanding?doi $=10.1037 \% 2 \mathrm{Fa} 0013073$

Hoogeboom, A.M.G. and Wilderom, C.P.M. (2019). A Complex Adaptive Systems Approach to Real-Life Team Interaction Patterns, Task Context, Information Sharing Vol 45 (1) 1-41. https:/journals sagepub com/ doi/10.1177/1059601119854927

Hoogeboom, A.M.G. Micro-behavioral Building Blocks of Effective Leadership, Followership and Team Interaction. PhD Thesis. 2019. University of Twente.
Available at: https://ris.utwente.nl/ws/portalfiles/ portal/162071586/PhD Dissertation Marcella Hoogeboom_Micro_behavioral_Building_Blocks of_Effective_Leadership_Followership_and_Team_ Interaction.pdf (accessed 8/6/2020)

\section{Personal Response}

Your study provides significant insight into the how this is linked to team effectiveness. How do you define "team effectiveness" and can it also vary according to routine or nonroutine tasks?

III In the study we asked whether the team members thought that the team accomplished its assigned tasks were used to assess the teams' effectiveness: whether the team was consistently a high performing team; team does high quality work; and whether the team is effective overall.

Thus, we captured the overall idea or perception of team members about how the team performed team accomplished specific goals). The perceptrat measure can be used in both a routine and notual task context as the teams' specific goals and key performance indicators were not comparable across the
different task contexts within this organisation. 